\title{
Determinants of Stretching Exercise Behavior among Office Employees using Health Promotion Model with Added Constructs
}

\author{
Mohammad Hossein Delshad, Sedigheh Sadat Tavafian, Anoshirvan Kazemnejad
}

\begin{abstract}
OBJECTIVE: To determinant the influencing factors on Stretching Exercise (SE) among office employees working in Shahid Beheshti University of Medical Sciences (SBUMS) in Iran through Health Promotion Model (HPM) with added constructs.

METHODOLOGY: Data were collected by a researcher-made and standard questionnaires based on HPM and added constructs of self-regulation, counter-conditioning, and stimulus control questionnaire regarding stretching exercise behavior among office employees working in comprehensive service centers affiliated to SBUMS. A multistage cluster sampling from May to Sep 2017 was done. To determinants the factors which effect on doing stretching exercise behavior; regression analysis was done through using SPSS 19 software.

RESULTS: Totally 420 office employees with mean age of $37.1 \pm 8.03$ years participated in this study. Perceived barriers to action $(B=-0.106, P<0.001)$, could prevent the studied participants from engaging in SE. However, perceived self efficacy $(B=0.172, P<0.001)$, commitment to a plan of action $(B=0.173$, $P=0.016)$, interpersonal influences $(B=0.099, P=0.003)$, and stimulus control $(B=0.193, P=0.007)$ were significant determinants for SE behavior.

CONCLUSION: This study showed that the office employees who were more perceived self efficacy, commitment to a plan of action, interpersonal influences, stimulus control and less perceived barriers were more likely to perform stretching exercise.
\end{abstract}

KEYWORDS: Health Promotion Model, Stretching Exercises, Employee.

This article may be cited as: Mohammad Hossein Delshad, Sedigheh Sadat Tavafian, Anoshirvan Kazemnejad. Determinants of Stretching Exercise Behavior among Office Employees using Health Promotion Model with Added Constructs. J Liaquat Uni Med Health Sci. 2019;18(02):152-9. doi: 10.22442/jlumhs.191820619

\section{INTRODUCTION}

Performing stretching exercises (SE) can reduce discomfort and pain and also increase the range of motion $^{1}$ consequently could reduce chronic musculoskeletal pain ${ }^{2}$. Specialists recommend that multidisciplinary biopsychosocial rehabilitation and physical exercise are a crucial component of pain ${ }^{3}$ Despite the fact that exercise programs have been proven to benefit people with pain $^{4-5}$. Physical inactivity in adults is highest in the eastern Mediterranean countries as well as Iran. Stretching exercise in adults protects against loss of mobility and will increase practical independence through increasing muscle mass, expanded bone density, and cardiovascular health ${ }^{6}$.

Sedentary behavior displays an inverse dose-reaction courting between sitting time and mortality, unbiased of the SE. The office employers, who work in Iranian universities, take a seat at their desk without engaging in stretching exercise for a long time ${ }^{7}$. Consequently, to determinant the factors influencing stretching exercise behavior, it is essential to many researchers and professionals who're engaged with designing proper educational interventions to elevate SE behavior amongst employers ${ }^{8}$.

The other constructs added of Pender's health Promotion model have been tested and diagnosed as the crucial determiners of the stretching exercise. The effective factors on the stretching among Iranian workplace operating have now not been diagnosed absolutely. Health promotion model (HPM) is one of comprehensive models by using which health behavior predictor factors like perceived barrier/ perceived benefit/ perceived self-efficacy and others could be determined ${ }^{9}$.

Therefore, it is necessary to search for opportunity models of health education delivery that could higher meet people preferences, and enhance or promote exercise behavior compliance ${ }^{10}$ therefore, the worksite health education programs could help office employees to enhance healthy behavior. In studies, the effects of substitution process modification, counter conditioning, self-regulation, and stimulus control, immediate competing demands and preferences were effective on exercising behavior ${ }^{11-13}$ 
For example, the most effective way to launch or start a behavior is to re-engineer control of the environment with help of stimulus controls ${ }^{14}$. They need also be regulated to avoid immediate competing demands and preferences. Moreover, stimulus control can manage the ability to behave and increase resistance in performing inappropriate behavior ${ }^{15}$.

Self-regulation is an effective factor because of setting goals and creating a program of forced and forced to identify the mechanisms and self-motivation, but a persistent and continuous challenge to the behavior is that sustaining behavior change is not easy. But by planning self-regulation, the behavior becomes easier. So, an individual attempting to change his behavior moves through a continuum of the program of forced $^{16}$. These model structures were located in (Figure I).

Earlier to designing the programs based on constructs added to HPM, the efficacy of this model on stretching exercise behavior and predicted powerful factors have to be taken into consideration. Thus this study aimed to determinant the influencing factors on stretching exercise (SE) among office employees working in Shahid Beheshti University of Medical Sciences (SBUMS) in Iran through Health Promotion Model (HPM) with added constructs.

\section{METHODOLOGY}

This cross-sectional study was performed among office employees of Shahid Beheshti University of Medical Sciences (SBUMS) located in Tehran, Iran from May 2017 to September 2017. Ethics committee of Tarbiat Modares University (TMU) confirmed the ethics principals (IR.TMU.REC.1395.329). To ensure confidentiality, office employees were asked not to provide their names in the questionnaires. All participants voluntarily signed the written consent form to be studied.

In this study 430 office employees who were working in three health networks of North, East and Shemiranat region affiliated to SBUMS and were satisfied to be studied and were recruited. The population, from which the study sample was selected, received their health services from urban health centers covered by the above health networks. Multi stage cluster sampling was applied to select the potential participants. In the first stage, the health networks of SBUMS were selected randomly from the ten health networks. Then, three health networks were selected randomly from the eight health centers in the health Networks. The sample size turned into estimated on the basis of 5 office employers for any item17. Therefore for a 77 item questionnaire a sample size of $(77 \times 5) 385$ were calculated.

In this cross-sectional study, the demographic characteristics questionnaire, self-reported questionnaires based on HPM with added constructs and a questionnaire regarding stretching exercise behaviors were used. According to the questionnaire of stretching exercise behaviors, participants were asked one question about performing due exercises like if they performed enough stretching exercise for an specific muscle such as neck stretching, shoulder stretching, and back extension exercises.

Enough stretched position time for each muscle was up to 10 to 30 seconds to be repeated 3 or 4 time, five days/week once every 20 minutes 1,18 . The answer for this question was a 2 option scale of Yes or No. This study was designed based on HPM constructs in previous study 19. The questionnaires regarding the other structures was made by the researchers, respectively based on the context of social cognitive theory and trans theoretical model constructs as self regulation, counter-conditioning, and stimulus control), and existed literature regarding stretching exercise and interview with key persons.

The facial validity of the questionnaire was done through qualitative and quantities' approaches. For qualitative approach, 15 office employees assessed each item for "ambiguity" relevancy", and "difficulty by which three items needed to be corrected.

In the quantitative method, the identical office employees have been asked to evaluate the questionnaire regarding the significance of every item on a five-point liker scale so one can calculate the impact score for each item. It was calculated as multiplying the significance of an item with its frequency (Impact Score = Frequency $(\%) \times$ Importance). All items were retained and identified as appropriate for subsequent analysis 20 .

The content validity of the questionnaires was confirmed by the experts' panel. These experts were 15 specialists, the specialist's panel reviewed all of the items and supplied their consultants with a questionnaire and evaluated the questionnaire. In this technique, nine questions from 86 questions reached the most settlement of professionals on "essential." These items were deleted. As an end result, seventy-seven items remained. Its reliability of the questionnaire was done by usage of Cronbach's alpha coefficient20. The Cranach alpha ranges for HPM with added constructs were from 0.73 to 0.91 , which confirmed the reliability of the structure.

The questions based on HPM with added constructs included the following sections. Perceived benefit of stretching exercise was assessed through an eight-item questionnaire. One of the questions was as "When I stretch my muscle, I feel better. Answers to the questions of this construct were evaluated in a 3-option scale from never to always. The rate for each 
statement was in a range of 1 to 3 . Therefore the total score for this questionnaire is from 8 to 24 points and the higher score shows better status.

Perceived barriers towards engaging in stretching exercise were evaluated through a nine-item questionnaire. One of the questions here was a: "Engaging in stretching exercise is a time-consuming behavior for me". Answers for this questionnaire were evaluated in a 4 option scale from never to always. The rate for each statement was in a range of 1 to four. Therefore the total score criterion was from 9 to 36 points and the higher score showed the worse position.

Perceived self-efficacy was assessed using a seven-item questionnaire. One of the items was as "I do stretching exercise regardless of my situation". Answers for this questionnaire were evaluated in a 4 option scale from never to always. Therefore the rate for each statement was in a range of 1 to 4 and the total score criterion was from 7 to 28 points, and the higher score showed better status.

Activity-related affect to passion was assessed with a seven-item questionnaire. One of these questions was as "Engaging in stretching exercise is enjoyable for me". The rate for each statement was evaluated through 3-option scale from never to always in a range of 1 to 3 . Therefore, the total score was from 7 to 21 points and the higher score showed better status.

Interpersonal influence was assessed using 5 item questionnaire. One of the questions was like: "How often the other computer operators or your co-workers expect you to do the stretching exercise". This question evaluated through a 5 option scale like 1 . Never 2. Sometimes 3. Often 4. Very often 5. Always, therefore the rate for this statement was from never to always in a range of 1 to 5 . The total score criterion was from 5 to 25 points and the higher score showed better status.

Situational influences were assessed using a nine-item questionnaire. One of these questions was "At my work engaging in stretching exercise is recommended". The rate for each statement was evaluated through a 3 option scale from never to always in a range of 1 to 4 . The score criterion is from 9 to 36 points 20 .

Commitment to a plan of action was assessed using an eight-item questionnaire. One of these questions was as "For engaging in stretching exercise, I reward myself". These questions were answered through a 4 option scale from never to always in a range of 1 to 4 . Therefore, the total score was from 8 to 32 points, and the higher score showed better status.

Immediate competing demands and preferences was assessed using 7-item questionnaire. One of these questions was "I enjoy engaging in stretching exercise while working with computer". Answers for these questions were evaluated through 2 option scale with a range of 1 to 2 . The last question was measured through 4 option scale. The total score criterion of the questionnaire was from 7 to 16 points, and the higher score showed better status. The maximum score was 16 because the last question was measured with a 4 option scale ranged from 1 to 4 .

Self Regulation of stretching exercise was assessed through a seven-item questionnaire. One of the questions was as "When I consider a particular goal for stretching, my motivation rises for doing it". Answers to the questions of this construct were evaluated in a 5 option scale from never to always. The rate for each statement was in a range of 1 to 5 . Therefore the total score for this questionnaire is from 7 to 35 points and the higher score shows better status.

Stimulus control towards engaging in stretching exercise was evaluated through a five-item questionnaire. One of the questions here was a: "I spend my rest time doing stretching exercises at workplace". Answers for this questionnaire were evaluated in a 5 option scale from never to always. The rate for each statement was in a range of 1 to five. Therefore the total score criterion was from 5 to 25 points and the higher score showed the worse position.

Counter conditioning was assessed using a 5 item questionnaire. One of the items was as "Instead of sitting at the computer desk and waiting for a tea, I prefer to go and make tea myself." Answers for this questionnaire were evaluated in a 3 option scale from never to always. Therefore the rate for each statement was in a range of 1 to 3 and the total score criterion was from 5 to 15 points, and the higher score showed better status 20 .

The stretching exercise behavior checklist was assessed using a 10 item questionnaire. Answers for these questions were evaluated by a 3 option scale with a range of 1 to 3 . Therefore, the total score was from 10 to 30 that the lower score was worse behavior $^{21}$.

Three self-administered questionnaires regarding the constructs of HPM, stretching exercise behavior and self-regulation, counter conditioning, stimulus control and demographic characteristics were designed to collect due data.

Data were entered into the SPSS software version 19 and analyzed through regression analysis. $\mathrm{P}<0.05$ was thought-out statistically substantial.

\section{RESULTS}

Totally 430 office employees recruited of which 420 individuals took part within the study and filled the 
query. $68.8 \%$ of samples were married. They worked 44 hours $( \pm 10.8)$ in a week. The body mass of half of subjects $(45.5 \%)$ was 150 or more. Based on the findings of this study, less than half of those office workers were classified as the active office workers. Table I shows other socio-demographic characteristics of the studied office employee. Table I shows the demographic characteristics of the participants.

The status of ranges, mean and standard deviation of the structures of the HPM with added constructs are shown in (Table II). In the present study, the mean scores of the commitment to plan, stimulus control were almost half of the accessible range, also the mean scores of the perceived benefits, perceived barriers, perceived self-efficacy, activity-related affect, interpersonal influences, immediate competing demands and preferences, situational influences, stretching exercise. Self-regulation and counter conditioning were higher than half of the accessible range.

Spearman's correlation tests were used to evaluate the relevance among the constructs of HPM with added constructs on stretching exercise behavior which is shown in Table III. As this table shows, there was an inverse significant correlation between stretching exercise and perceived barriers to action; in order that the office employees who perceived more barriers for behavior were less likely to do engage stretching exercise significantly ( $p$-value $<0.001)$.

A logistic regression models for "Yes" and "No" stretching exercise was done with linear regression analysis shows in Table IV. Generally, the structures predicted up to $56 \%$ of the stretching exercise behavior variance in which the regression analysis suggested significant correlation of the prediction ability of the suggested the nearly significant correlation between the conditional effectors. Regression analysis showed that the forecast of self-efficacy, commitment to plan,

Perceived barriers $(B=-0.106, P<0.001)$. Interpersonal influences and Stimulus control are significant for stretching exercise behavior and situational influences are nearly significant. Self-efficacy $(B=$ $0.172, P<0.001)$, commitment to plan $(B=0.173$, $P=0.016)$, interpersonal influences $(B=0.099$, $\mathrm{P}=0.003)$, and stimulus control $(B=0.193, P=0.007)$ were positive predictors for the stretching exercise behavior. Immediate competing demands and preferences $(B=0.017, P=0.741)$, self-regulation $(B=$ -0.003, $P=0.933)$ and counter conditioning $(B=0.012$, $\mathrm{P}=0.841$ ) were the negligible predictability in stretching exercise (Table IV).
TABLE I: SOCIO-DEMOGRAPHIC CHARACTERISTICS OF THE STUDIED OFFICE EMPLOYEE

\begin{tabular}{|c|c|c|c|}
\hline $\begin{array}{l}\text { Studied variables } \\
\text { and Constructs }\end{array}$ & Sufficient & $\mathbf{N}(\%)$ & Mean (SD) \\
\hline Age & $\begin{array}{l}21-29 \\
30-39 \\
40 \text { and } \\
\text { above }\end{array}$ & $\begin{array}{r}71(16.9) \\
184(438) \\
165(39.3)\end{array}$ & $37.1 \pm 8.03$ \\
\hline $\begin{array}{l}\text { Work experience } \\
\text { with computer (yrs) }\end{array}$ & $\begin{array}{l}\leq 5 \text { years } \\
5-10 \text { years } \\
11-15 \text { years } \\
16-20 \text { years } \\
\geq 20\end{array}$ & $\begin{array}{r}220(52.4) \\
121(28.8) \\
55(13.1) \\
23(5.5) \\
1(0.2)\end{array}$ & $1.72 \pm 0.9$ \\
\hline Gender & $\begin{array}{l}\text { Male } \\
\text { female }\end{array}$ & $\begin{array}{l}113(26.9) \\
307(73.1)\end{array}$ & - \\
\hline $\begin{array}{l}\text { Suffering from } \\
\text { WRMSD pain }\end{array}$ & $\begin{array}{l}\text { Yes } \\
\text { No }\end{array}$ & $\begin{array}{l}154(36.6) \\
266(63.6)\end{array}$ & - \\
\hline Marital status & $\begin{array}{l}\text { Single } \\
\text { Married }\end{array}$ & $\begin{array}{l}131(31.2) \\
289(68.8)\end{array}$ & - \\
\hline Address & $\begin{array}{l}\text { City } \\
\text { Village }\end{array}$ & $\begin{array}{r}415(98.8) \\
5(1.2)\end{array}$ & - \\
\hline $\begin{array}{l}\text { Classification } \\
\text { of Stretching } \\
\text { Exercise at the } \\
\text { beginning of the } \\
\text { study }\end{array}$ & $\begin{array}{l}\text { Inactive } \\
\text { minimally } \\
\text { active } \\
\text { Active }\end{array}$ & $\begin{array}{r}229(54.6) \\
103(24.5) \\
88(21)\end{array}$ & - \\
\hline
\end{tabular}

TABLE II: DESCRIPTIVE STATISTICS FOR THE HPM WITH ADDED CONSTRUCTS AND STRETCHING EXERCISE

\begin{tabular}{|l|c|c|}
\hline \multicolumn{1}{|c|}{ Range Observed } & Mean \pm SD & $\begin{array}{c}\text { Description } \\
\text { Scale }\end{array}$ \\
\hline Perceived benefits & $17.90 \pm 5.05$ & $8-24$ \\
\hline Perceived barriers & $20.31 \pm 6.03$ & $9-36$ \\
\hline Perceived Self efficacy & $17.15 \pm 3.71$ & $7-28$ \\
\hline Activity-Related affect & $16.27 \pm 2.45$ & $7-21$ \\
\hline Interpersonal influences & $11.55 \pm 4.64$ & $5-25$ \\
\hline Commitment to plan & $16.82 \pm 4.28$ & $8-32$ \\
\hline $\begin{array}{l}\text { Immediate competing } \\
\text { demands and preferences }\end{array}$ & $11.70 \pm 2.80$ & $7-16$ \\
\hline Situational influences & $14.21 \pm 4.59$ & $9-36$ \\
\hline Stretching exercise (SE) & $17.64 \pm 2.48$ & $10-30$ \\
\hline Self Regulation & $19.71 \pm 4.98$ & $7-35$ \\
\hline Counter conditioning & $12.41 \pm 2.53$ & $5-15$ \\
\hline Stimulus control & $11.99 \pm 2.80$ & $5-25$ \\
\hline
\end{tabular}


Mohammad Hossein Delshad, Sedigheh Sadat Tavafian, Anoshirvan Kazemnejad

\section{TABLE III: CORRELATION MATRIX FOR STRUCTURES THE HPM WITH ADDED CONSTRUCTS AND} STRETCHING EXERCISE BEHAVIOR

\begin{tabular}{|c|c|c|c|c|c|c|c|c|c|c|c|c|c|}
\hline & Variable & 1 & 2 & 3 & 4 & 5 & 6 & 7 & 8 & 9 & 10 & 11 & 12 \\
\hline 1 & Perceived benefits of Action & 1.000 & & & & & & & & & & & \\
\hline 2 & Perceived barriers to action & $-.383^{* *}$ & 1.000 & & & & & & & & & & \\
\hline 3 & Perceived Self efficacy & $.423^{* *}$ & $-.660^{* *}$ & 1.000 & & & & & & & & & \\
\hline 4 & Activity-Related affect & $.371^{* \star}$ & $-.113^{*}$ & $.342^{* *}$ & 1.000 & & & & & & & & \\
\hline 5 & Interpersonal influences & $.453^{* *}$ & $-.585^{* \star}$ & $.583^{* *}$ & $.282^{* \star}$ & 1.000 & & & & & & & \\
\hline 6 & Commitment to plan of action & $.730^{* \star}$ & $-.509^{* \star}$ & $.709^{* \star}$ & $.510^{\star \star}$ & $.627^{\star \star}$ & 1.000 & & & & & & \\
\hline 7 & $\begin{array}{l}\text { Immediate competing } \\
\text { demands and preferences }\end{array}$ & .050 & -.040 & .003 & .021 & $.130^{* *}$ & .073 & 1.000 & & & & & \\
\hline 8 & Situational influences & $.129^{* *}$ & -.008 & $.098^{*}$ & .092 & $.145^{\star *}$ & $.197^{\star *}$ & .065 & 1.000 & & & & \\
\hline 9 & Stretching Exercise & $.327^{* *}$ & $-.523^{* *}$ & $.581^{* *}$ & $.208^{* *}$ & $.540^{* *}$ & $.558^{* \star}$ & .076 & $.107^{*}$ & 1.000 & & & \\
\hline 10 & Self Regulation & $.203^{* *}$ & $-.118^{*}$ & $.195^{* *}$ & $.242^{* *}$ & $.227^{* *}$ & $.331^{* *}$ & $.261^{* *}$ & $.505^{* *}$ & $.212^{* *}$ & 1.000 & & \\
\hline 11 & Counter conditioning & .004 & $-.137^{* \star}$ & $.167^{* *}$ & .051 & .082 & $.131^{* *}$ & $.117^{*}$ & $.136^{* *}$ & $.158^{* *}$ & $.120^{*}$ & 1.000 & \\
\hline 12 & Stimulus control & $.120^{*}$ & -.026 & $.114^{*}$ & $.128^{* *}$ & $.153^{* *}$ & $.195^{* \star}$ & $.181^{* *}$ & $.559^{* *}$ & $.189^{* *}$ & .026 & $.137^{* *}$ & 1.000 \\
\hline
\end{tabular}

Spearman's**. Correlation is meaningful at 0.01 levels (2-sided). * Correlation is meaningful at the 0.05 level (2-sided).

TABLE IV: REGRESSION ANALYSIS OF THE STRETCHING EXERCISE BEHAVIOR'S FACTORS BASED ON THE HPM WITH ADDED CONSTRUCTS

\begin{tabular}{|l|c|c|c|c|c|}
\hline \multicolumn{1}{|c|}{ Dependent Variable } & OR & P-Valve & S.E & B & Independent variable \\
\hline Perceived benefits & -0.031 & 0.043 & 0.471 & 0.970 & 0.900 \\
\hline Perceived barriers & -0.106 & 0.038 & 0.005 & 1.188 \\
\hline Perceived Self efficacy & 0.172 & 0.061 & 0.004 & 0.890 \\
\hline Activity-Related affect & -0.116 & 0.073 & 0.112 & 1.104 \\
\hline Interpersonal influences & 0.099 & 0.046 & 0.003 & Stretching Exercise \\
(SE) & 0.173 & 0.072 & 0.016 & 1.188 \\
\hline Commitment to plan & 0.017 & 0.053 & 0.741 & 1.018 \\
\hline Situational influences & -0.057 & 0.040 & 0.158 & 0.945 \\
\hline Counter conditioning & -0.012 & 0.060 & 0.841 & 0.988 \\
\hline Stimulus control & 0.193 & 0.076 & 0.007 & 1.213 \\
\hline Self Regulation & -0.003 & 0.035 & 0.933 & 0.997 & \\
\hline
\end{tabular}

Cox \& Snell $R$ Square: .408, Nagelkerke $R$ Square: .560, Percentage Correct: 64.0 percent

\section{DISCUSSION}

This study was done to show better understand why adult individuals do not engage in stretching exercise. The findings of this study showed that the Pender's Health Promotion Model with added constructs could effect on stretching exercise behavior as it was shown in previous study ${ }^{22}$. Based on the results of this study, the structures of the HPM with added constructs were $56 \%$ of the variance of stretching exercise behavior compared to the Pender model structures.

According to the results of this study, perceived self efficacy, commitment to a plan of action, interpersonal influences, and stimulus control were the influential predictors of engaging in stretching exercise behavior among office employees. The perceived barriers to action could prevent the studied participants from engaging in stretching exercise. The results of this study repeat the results of the previous studies ${ }^{22-26}$. 


\section{FIGURE I: SCHEMATIC REPRESENTATION OF THE BASED ON HEALTH PROMOTION MODEL (HPM) WITH ADDED CONSTRUCTS}

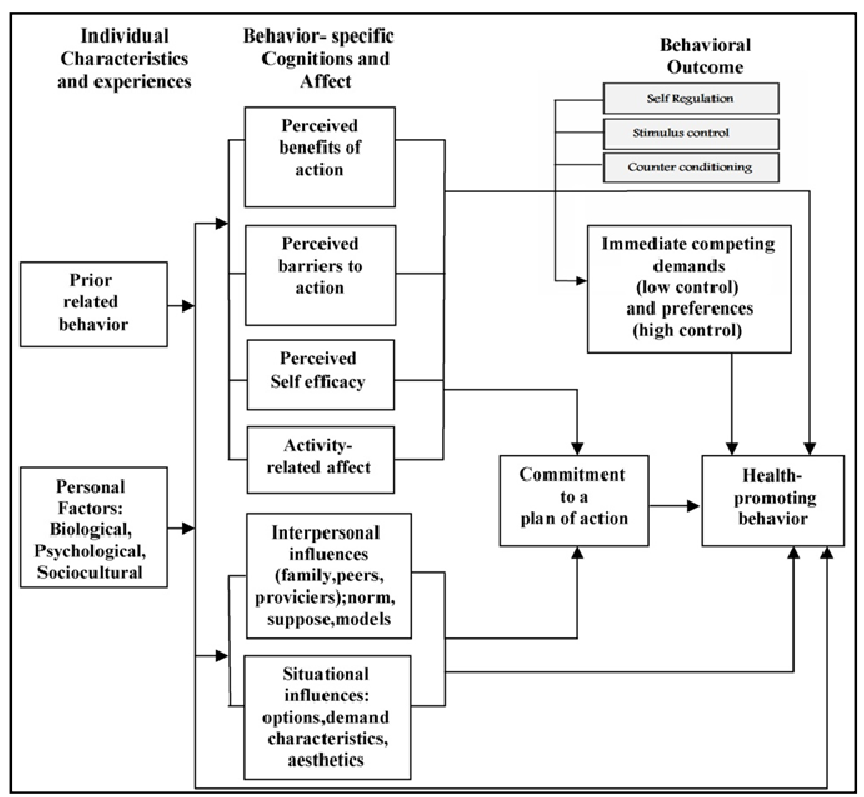

On the other hand, there was no clear relationship between self-regulation and stretching exercise. In Tobin D $2017^{23}$ study, similarly, there was no relationship between self-regulation and exercise. In the Schöndube A $2016^{24}$ study opposed this study were associated with positive power level stimulus control with exercise $(P=0.01)$. Furthermore, in the previous study, there was no significant decrease in perceived self-efficacy and perceived barriers ${ }^{25}$.

It can be said that one of the roles of stimulus control (The controlling of various stimuli which triggers undesirable and unwanted behaviors). Consequently, identifying and eliminating internal and external stimuli that creates unhealthy habits, behavior, and on the other hand, quick addition of healthy options, like stretching exercise, to change our environment or the benefit of the healthy environment with the self-help group, avoidance, and environment re-engineer strategy.

Interpersonal influences structure third top and the most powerful in predicting structure exercise behavior. On the other hand, family and friends are supporting direct and positive forecast for physical behavior and activity. While Chen $Y 2017^{26}$ showed that family and friends support had lower effect on physical predictions preventing the activity of watching television. Mayer JD $2017^{27}$ suggested that emotional support is an important factor in the promotion of physical activity among people. It was suggested that office employers get support from their coworkers in order to persuade the coworkers to participate in stretching exercise.
The current study showed the application of HPM with added constructs for further studies. In this regard, HPM with added constructs should be improved more for office employee's perceived self-efficacy, perceived barriers and commitment to plan of action as well as interpersonal influences and stimulus control.

\section{CONCLUSION}

Findings of this study provided this fact that perceived barrier by the office employees may prevent them from engaging in stretching exercise while being commitment to plan action or interpersonal influences or stimulus control cause engaging in the exercises. Therefore, it could be suggested that the proper intervention based on these predictors should be designed to motivate the office employees to do the exercises. Using HPM with added constructs is more effective than the original HPM model. However, doing more studies to ensure these results are recommended.

\section{Limitations}

There are some limitations to this study. First, the data were collected via self-report that would intervene with the outcomes of this study. Moreover, the office employees were selected from one university. However, regardless of the restrictions described above, this study showed HPM as a theoretical framework to predict stretching exercise in office employees in Iran.

Ethical Permission: Ethics committee of Tarbiat Modares University (TMU) confirmed the ethics principals (IR.TMU.REC.1395.329) dated: 03-05-2016.

Conflict of interest: There was no any conflict of interest.

Funding: University funded project.

\section{REFERENCES}

1. Gasibat Q, Simbak NB, Aziz AA, Petridis L, Tróznai $Z$. Stretching exercises to prevent workrelated musculoskeletal disorders: A review article. Am J Sports Sci Med. 2017; 5(2): 27-37. doi: 10.12691/ajssm-5-2-3

2. Skarpsno ES, Nilsen TIL, Sand T, Hagen K, Mork PJ. Physical work exposure, chronic musculoskeletal pain and risk of insomnia: longitudinal data from the HUNT study, Norway. Occup Environ Med. 2018; 75(6): 421-26. doi: 10.1136/oemed-2018-105050.

3. Iversen VM, Vasseljen O, Mork PJ,Gismervik S, Bertheussen GF, Salvesen O, et al. Resistance band training or general exercise in 
multidisciplinary rehabilitation of low back pain? A randomized trial. Scand J Med Sci Sports. 2018; 28(9): 2074-83. doi: 10.1111/sms. 13091.

4. López-de-Uralde-Villanueva I, Muñoz-García D, Gil-Martínez A, Padro-Montero J, Munez-Plata R, Angulo-Diaz-Parreno $S$, et al. A Systematic Review and Meta-Analysis on the Effectiveness of Graded Activity and Graded Exposure for Chronic Nonspecific Low Back Pain. Pain Med. 2016; 17 (1): 172-188.

5. Searle A, Spink M, Ho A, Chuter V. Exercise interventions for the treatment of chronic low back pain: a systematic review and meta-analysis of randomised controlled trials. Clin Rehabil. 2015; 29(12): 1155-1167. doi: 10.1177/0269215515570 379.

6. Kisner C, Colby LA, Borstad J, editors. Therapeutic Exercise: Foundations and Techniques. $7^{\text {th }}$ ed. F.A. Davis Company; 2017.

7. Mohammed M, Naji FL. Benefits of Exercise Training For Computer-Based Staff: A Meta Analyses. Int J Kinesiol Sports Sci. 2017; 5(2): 1623. doi:10.7575/aiac.ijkss.v.5n.2p.16.

8. Ivarsson A, Johnson U, Andersen MB, Tranaeus $U$, Stenling A, Lindwall M. Psychosocial factors and sport injuries: meta-analyses for prediction and prevention. Sports Med. 2017; 47(2): 353-365. doi: 10.1007/s40279-016-0578-x.

9. Pender NJ, Murdaugh CL, Parsons MA. Health promotion in nursing practice. $7^{\text {th }}$ Ed. Pearson, Boston USA. 2015.

10. Chhabra H, Sharma S, Verma S. Smartphone app in self-management of chronic low back pain: a randomized controlled trial. Eur Spine J. 2018; 27 (11): 2862-74. doi: 10.1007/s00586-018-5788-5.

11. Foxall G. Advanced Introduction to Consumer Behavior Analysis. Edward Elgar Publishing; United Kingdom. 2017.

12. Ainslie G. De Gustibus Disputare: Hyperbolic delay discounting integrates five approaches to impulsive choice. J Econ Method. 2017; 24(2): 166-189. doi: 10.1080/1350178X.2017.1309373.

13. Bach DR, Dayan P. Algorithms for survival: a comparative perspective on emotions. Nat Rev Neurosci. 2017; 18(5): 311-319. doi: 10.1038/nrn. 2017.35.

14. Olson K, Bond D, Wing RR. Behavioral Approaches to the Treatment of Obesity. R I Med J. (2013). 2017; 100(2): 21-24.

15. Doherty O, McGreevy PD, Pearson G. The importance of learning theory and equitation science to the veterinarian. Appl Animal Behav Sci. 2017; 190: 111-122. doi:10.1016/j.applanim. 2017.02.012

16. Maruf FA, Umunnah JO, Akindele MO. Associations of Constructs of Transtheoretical Model With Physical Activity Behavior Among Individuals With Essential Hypertension. Cardiopulm Phys Ther J. 2017; 28(1): 12-21.

17. Munro BH, editor. Statistical methods for Health Care Research. vol 1. Philadelphia: Lippincott Williams \& Wilkins; 2005.

18. Sihawong $R$, Janwantanakul $P$, Sitthipornvorakul E, Pensri P. Exercise therapy for office workers with nonspecific neck pain: a systematic review. J Manipulative Physiol Ther. 2011;34(1):62-71. doi: 10.1016/j.jmpt.2010.11.005.

19. Delshad M, Tavafian S, Kazemnejad A. Factors predicting the stretching exercise behaviors of the office employees working in the Shahid Beheshti University of Medical Sciences in Tehran, Iran. . Rev Inves Clin. 2019; 71:171-85. doi: 10.24875/ RIC.18002694

20. Delshad MH, Tavafian SS, Kazemnejad A. Designing and psychometric evaluation of Stretching Exercise Influencing Scale (SEIS) BMJ Open 2019; 9(5): e026565. doi: 10.1136/bmjopen2018-026565

21. Delshad MH, Tavafian SS, Kazemnejad A. Educational intervention for promoting stretching exercise behavior among a sample of Iranian office employees: applying the Health Promotion Model. J Pain Res. 2019; 12:733-742. doi:10.2147/ JPR.S183410

22. McEachan RRC, Conner M, Taylor NJ, Lawton RJ. Prospective Prediction of Health-Related Behaviours with the Theory of Planned Behaviour: A meta-analysis. Health Psychol Rev. 2011; 5(2): 97-144. doi:10.1080/17437199.2010.521684

23. Tobin D, Munroe-Chandler K, Hall C, Guerrero M, Shirazipour C, Cooke L. Examining the relationship between children's active play imagery and basic psychological needs. Int $\mathrm{J}$ Sport Exercise Psychol. 2017; 15(1): 92-102. doi:10.1080/1612197X.2015.1069875

24. Schöndube A, Bertrams A, Sudeck G, Fuchs R. Self-control strength and physical exercise: An ecological momentary assessment study. Psychol Sport Exercise. 2017; 29: 19-26. doi:10.1016/ j.psychsport.2016.11.006 
25. Gnilka PB, Novakovic A. Gender Differences in STEM Students' Perfectionism, Career Search Self-Efficacy, and Perception of Career Barriers. J Counsel Develop. 2017; 95(1): 56-66.

26. Chen Y, Gao Q, Rau P-LP. Watching a Movie Alone yet Together: Understanding Reasons for Watching Danmaku Videos. Int J
Human-Computer Interaction. 2017; 33(9): 731743. doi:10.1080/10447318.2017.1282187.

27. Mayer JD, Skimmyhorn W. Personality attributes that predict cadet performance at West Point. J Res Personality. 2017; 66:14-26. doi:10.1016/ j.jrp.2016.10.012.

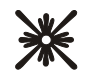

AUTHOR AFFILIATION:

Mohammad Hossein Delshad

Department of Health Education and Health Promotion

Faculty of Medical Sciences, Tarbiat Modares University, Tehran, Iran.

Sedigheh Sadat Tavafian (Corresponding Author)

Professor, Department of Health Education and Health Promotion

Faculty of Medical Sciences, Tarbiat Modares University,Tehran, Iran.

Email: tavafian@modares.ac.ir

\section{Anoshirvan Kazemnejad}

Professor, Department of Biostatistics

Faculty of Medical Sciences, Tarbiat Modares University, Tehran, Iran. 